\title{
Effects of postmortem heparinization in canine lung transplantation with non-heart-beating donors
}

Hidetoshi Inokawa, MD

Hiroshi Date, MD

Mikio Okazaki, MD

Daisuke Okutani, MD

Keiju Aokage, MD

Itaru Nagahiro, MD

Motoi Aoe, MD

Yoshifumi Sano, MD

Nobuyoshi Shimizu, MD

From the Department of Cancer and Thoracic Surgery (Surgery II), Okayama University Graduate School of Medicine and Dentistry, Okayama, Japan.

Supported by the Research Grant for Cardiovascular Diseases (12C-6) from the Ministry of Health, Labor and Welfare, Japan.

Received for publication Feb 3, 2004; revisions received May 2, 2004; accepted for publication May 6, 2004.

Address for reprints: Hiroshi Date, MD, Department of Cancer and Thoracic Surgery (Surgery II), Okayama University Graduate School of Medicine and Dentistry, 2-5-1 Shikata Cho, Okayama 7008558, Japan (E-mail: hdate@ nigeka2. hospital.okayama-u.ac.jp).

J Thorac Cardiovasc Surg 2005;129:429-34 $0022-5223 / \$ 30.00$

Copyright (c) 2005 by The American Association for Thoracic Surgery

doi:10.1016/j.jtcvs.2004.05.009
Objective: Microthrombus formation appears to be one of the major detrimental factors in lung transplantation from non-heart-beating donors. The purpose of this study was to evaluate the effects of postmortem heparinization by closed-chest cardiac massage in a canine model of left single-lung allotransplantation from non-heart-beating donors.

Methods: Left lung transplantation was performed in 18 weight-matched pairs of mongrel dogs. Donors were killed with an intravenous injection of potassium chloride and left at room temperature for 2 hours. The cadaveric donors were assigned randomly to one of the three groups. In group $1(\mathrm{n}=6)$, no heparin was given as a control. In group $2(n=6)$, heparin sodium $(1000 \mathrm{U} / \mathrm{kg})$ was administered intravenously before cardiac arrest. In group $3(n=6)$, heparin sodium $(1000$ $\mathrm{U} / \mathrm{kg}$ ) was administered intravenously 10 minutes after death, then closed-chest cardiac massage was performed for 2 minutes. After 2 hours of cardiac arrest, donor lungs were flushed with low-potassium dextran-glucose solution and preserved for 60 minutes. After left lung transplantation, the right pulmonary artery was ligated, and recipient animals were followed up for 3 hours. Univariate and multivariate repeated analyses were used for statistics.

Results: Both groups 2 and 3 had significantly better gas exchange and lower pulmonary vascular resistance than group 1 . Changes in thrombin-antithrombin III complex concentration during the warm ischemia indicated that postmortem heparinization suppressed clotting activation in the donor.

Conclusions: Postmortem heparinization by cardiac massage is beneficial in lung transplantation from non-heart beating donors by preventing microthrombus formation.

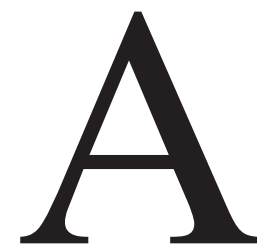

great disparity between the supply of donor organs and the demand of potential recipients has resulted in longer waiting times and annual increases in deaths on the lung transplant waiting list. As a consequence, efforts have been directed toward the use of non-heart-beating donors. Since Steen and colleagues ${ }^{1}$ described the first successful human lung transplantation from an "uncontrolled" non-heart-beating donor in 2001, interest in non-heart-beating donors has seen a recent resurgence. 
Previous experimental studies have shown that a safe period of ischemia for the lungs at normothermia is less than 2 hours without heparinization, ${ }^{2}$ but this could be extended to 4 hours when the lungs were fully heparinized and ventilated before cardiac arrest. ${ }^{3}$ However, heparinizing the donor before death for the purpose of organ donation requires consensus on ethics. With uncontrolled non-heartbeating donors, heparinization before death is practically impossible. In this study, we have evaluated the effects of postmortem heparinization by closed-chest cardiac massage in a canine model of left single-lung allotransplantation from non-heart-beating donors.

\section{Material and Methods}

Eighteen weight-matched pairs of adult mongrel dogs (7.0-25.0 $\mathrm{kg}$ ) were used for left single-lung allotransplantation. Donor animals were premedicated with intramuscular injection of ketamine hydrochloride $(15 \mathrm{mg} / \mathrm{kg})$ and atropine sulfate $(0.025 \mathrm{mg} / \mathrm{kg})$. They were then anesthetized by intravenous injection of thiopental sodium $(7.5 \mathrm{mg} / \mathrm{kg})$ and pancuronium bromide $(0.2 \mathrm{mg} / \mathrm{kg})$ and intubated. The donors were mechanically ventilated with $100 \%$ oxygen and killed with an intravenous injection of potassium chloride. Cardiac arrest was confirmed by electrocardiography. The ventilator was stopped and disconnected from the intubated endotracheal tube. The animals were secured on the table in the supine position and left at room temperature for 2 hours.

The cadaveric donors were assigned randomly to one of the three groups. In group $1(\mathrm{n}=6)$, no heparin was given, for control. In group $2(\mathrm{n}=6)$, heparin sodium $(1,000 \mathrm{U} / \mathrm{kg})$ was administered intravenously before cardiac arrest. In group $3(n=6)$, heparin sodium $(1,000 \mathrm{U} / \mathrm{kg})$ was administered intravenously 10 minutes after death, then closed chest cardiac massage was performed for 2 minutes to distribute the heparin around the circulatory system. Chest compressions were provided 30 times per minute to maintain the systolic arterial pressure around 50 to $60 \mathrm{~mm} \mathrm{Hg}$.

To measure the degree of clotting activation, the concentration of the clotting marker thrombin-antithrombin III (TAT) complex was measured in citrate-anticoagulated plasma by enzyme-linked immunosorbent assay. ${ }^{4}$ Serial blood samples were taken from donors before death and 30, 60, 90, and 120 minutes after death through a femoral arterial catheter. In group 3, activated coagulation time (ACT) was measured after cardiac massage.

After 2 hours of cardiac arrest, a median sternotomy was performed. The main pulmonary artery was opened, and the left atrial appendage was incised. Postmortem thrombus in the pulmonary artery and left atrium was evacuated as much as possible. A $20 \mathrm{~F}$ catheter was inserted into the main pulmonary artery and secured. Ventilation was established at a tidal volume of $20 \mathrm{~mL} /$ $\mathrm{kg}$, a respiratory rate of $15 \mathrm{breaths} / \mathrm{min}$, and a positive endexpiratory pressure of $5 \mathrm{~cm} \mathrm{H}_{2} \mathrm{O}$. The heart-lung block, ventilated with $100 \%$ oxygen, was perfused with $50-\mathrm{mL} / \mathrm{kg}$ low-potassium dextran-glucose solution ${ }^{5}$ stored at $4^{\circ} \mathrm{C}$ from a bag that was hung $50 \mathrm{~cm}$ above the chest. Semi-inflated lung block was excised, submerged in cold saline solution, and stored at $4^{\circ} \mathrm{C}$ for 60 minutes.
The recipient animals were sedated in the same manner as the donors. Anesthesia was maintained with a 50:50 mixture of nitrous oxide and oxygen and $0.3 \%$ to $1.0 \%$ halothane. A thermodilution catheter was placed in the main pulmonary artery from the right external jugular vein to measure pulmonary arterial pressure, central venous pressure, and cardiac output. Aortic pressure was measured by a femoral artery line. With the animal in the right lateral decubitus position, a thoracotomy was performed in the left fifth intercostal space, followed by a left pneumonectomy. The right pulmonary artery was encircled with 1-0 silk string. A 5F catheter was inserted into the left atrial appendage to measure left atrial pressure.

On a back table, the left lung, which was to be used for implantation, was trimmed from the donor lung block. The donor right lung was used for histologic study.

Left lung implantation was then performed in the usual fashion. After transplantation, both lungs were ventilated with a tidal volume of $20 \mathrm{~mL} / \mathrm{kg}$ and a positive end-expiratory pressure of $5 \mathrm{~cm}$ $\mathrm{H}_{2} \mathrm{O}$ at a respiratory rate of 15 breaths/min and an inspired oxygen concentration of 1.0. The baseline measurement was done. Then the right pulmonary artery was ligated 15 minutes after reperfusion so that we could measure the function of the transplanted left lung. Aortic pressure, pulmonary arterial pressure, central venous pressure, left atrial pressure, and airway pressure were continuously recorded. Cardiac output and arterial blood gas values were measured periodically (30 minutes, 60 minutes, 90 minutes, 120 minutes, 150 minutes, and 180 minutes after ligation of the right pulmonary artery).

\section{Animal Care}

All dogs received humane care in compliance with the "Principles of Laboratory Animal Care" formulated by the National Society for Medical Research and the "Guide for the Care and Use of Laboratory Animals" (http://www.nap.edu/catalog/5140.html).

\section{Statistics}

Univariate and multivariate repeated analyses were used to determine whether an overall difference existed in lung function and in TAT complex data among the three groups during the 3-hour assessment period. Multiple group comparisons were made with contrasts. Results are expressed as mean \pm SEM.

\section{Results}

There were no significant differences among the three groups in donor weight, recipient weight, flushing time, harvesting time, preparation time, or implantation time. The flushing times were $269 \pm 53$ seconds in group 1, $226 \pm 52$ seconds in group 2, and $213 \pm 48$ seconds in group 3 (differences not significant). The total ischemic times were $275 \pm 15$ minutes in group $1,271 \pm 14$ minutes in group 2, and $284 \pm 14$ minutes in group 3 (differences not significant). After left lung allotransplantation, all 18 animals tolerated the right pulmonary artery ligation and survived the 3-hour assessment period. 
TABLE 1. Assessment of lung and cardiac function of recipients

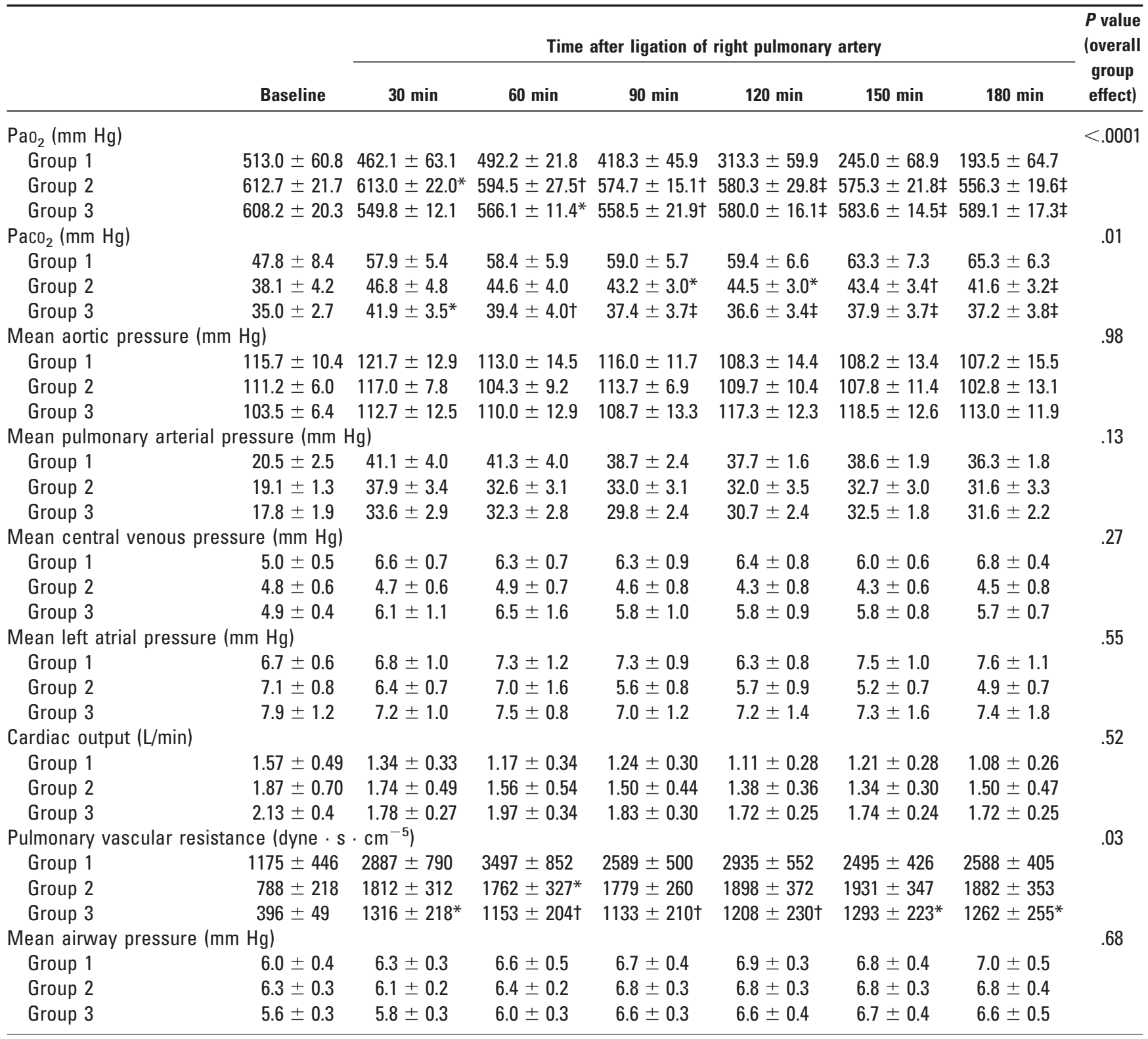

All values are given as mean \pm SEM.

$* P<.05$ versus group 1 .

$\dagger P<.01$ versus group 1 .

$\ddagger P<.001$ versus group 1 .

\section{Lung Function Study}

The results of gas exchange and hemodynamic evaluation of the recipients during the 3-hour assessment period are shown in Table 1. Among the various functional indicators, three valuables $\left(\mathrm{PaO}_{2}, \mathrm{PaCO}_{2}\right.$, and pulmonary vascular resistance) had a significant group effect $(P<.001$, $P=.01$, and $P=.03$, respectively). Regarding these three valuables, all three comparisons (group 1 vs group
2, group 1 vs group 3, and group 2 vs group 3) for each time point were performed. $\mathrm{PaO}_{2}$ was significantly better in groups 2 and 3 than in group 1 . $\mathrm{PaCO}_{2}$ was significantly lower in groups 2 and 3 than in group 1. Pulmonary vascular resistance was significantly lower in groups 2 and 3 than in group 1 . There were no significant differences between groups 2 and 3 in these three functional indicators. There were no significant group effects in 


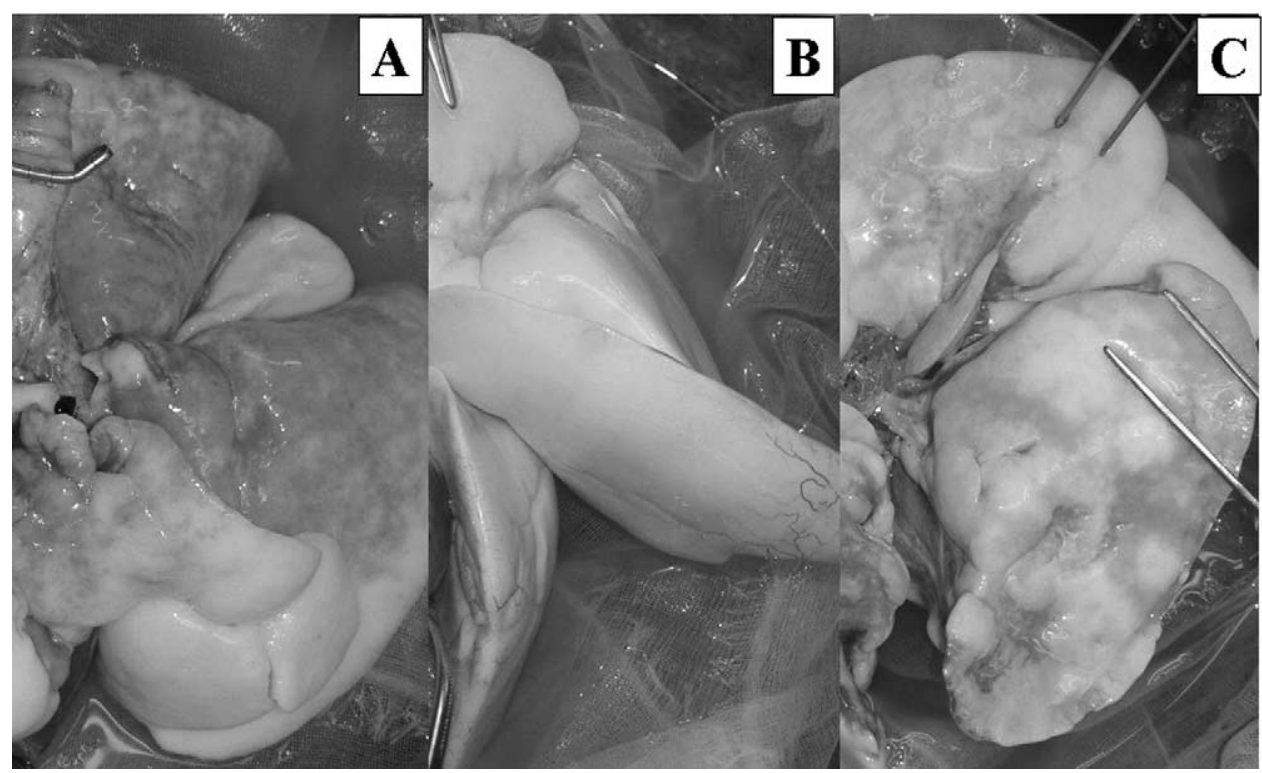

Figure 1. Macroscopic findings of donor lung after pulmonary flushing with low-potassium dextran-glucose solution in each group. A, Donor left lung in group 1. Lung surface looked patchy, indicating inhomogeneous perfusion. Poorly perfused area was seen on dorsal side. B, Donor left lung in group 2. Lung surface looked uniformly perfused. C, Donor left lung in group 3. Patchy area was less observed in group 3 than in group 1.

mean aortic pressure, mean pulmonary arterial pressure, mean central venous pressure, mean left atrial pressure, cardiac output, and mean airway pressure.

\section{Macroscopic and Microscopic Findings}

In group 1, the donor lung surface looked patchy macroscopically after pulmonary flush, indicating inhomogeneous perfusion (Figure 1, A). The poorly perfused area was seen in the dorsal side of the donor lung. In group 2, the whole donor lung surface looked uniformly perfused (Figure 1, B). The patchy area was less observed in group 3 than in group 1 (Figure 1,C).

Histologic studies of samples of lung parenchyma obtained after pulmonary flushing demonstrated many residual blood cells or blood clots in group 1 (Figure 2, A). These blood cells or blood clots were less observed in groups 2 and 3 (Figure 2, $B$ and $C$ ).

\section{TAT Complex}

The changes in TAT complex concentration in each group are shown in Figure 3. The TAT complex concentration in group 1 increased significantly after death, and it was significantly higher than in groups 2 and 3 after 60 minutes of warm ischemic time $(P<.001)$. On the other hand, concentrations were stable in both groups 2 and 3 after death, and there was no significant difference between the two groups.

\section{ACT}

In group 3, ACT measured after cardiac massage exceeded 1500 seconds in all 6 cadaveric donors.

\section{Discussion}

In response to the growing demand for lung transplantation, efforts have been directed toward the use of living-donors, ${ }^{6,7}$ marginal donors, ${ }^{8}$ and non-heart-beating donors. ${ }^{1}$ Ischemic injury is minimized in the case of heart-beating donors because cessation of circulation occurs simultaneously with perfusion of preservation solution and rapid cooling. Use of a non-heart-beating donor imposes ischemic injury caused by prolonged circulatory arrest in warm temperature.

Several investigators ${ }^{2,3,9}$ have conducted examinations of the lung's tolerance of warm ischemia. It has been proved that lung cells remain viable by metabolizing the oxygen in the alveoli for a certain period even at warm temperatures without circulation. ${ }^{10} \mathrm{~A}$ safe period for the lungs at normothermia is less than 2 hours without heparinization. ${ }^{2}$ Ulicny and colleagues ${ }^{3}$ demonstrated that the acceptable warm ischemic time could be extended to 4 hours when the lungs were fully heparinized before cardiac arrest and kept ventilated after death. A number of strategies have been developed in an attempt to reduce warm ischemic injury: oxygen radical scavengers, ${ }^{11}$ topical cooling, ${ }^{12}$ leukocyte depletion, ${ }^{13}$ inhaled nitric oxide, ${ }^{14}$ fibrinolytic drugs,,${ }^{15}$ and retrograde pulmonary flush. ${ }^{16}$ 


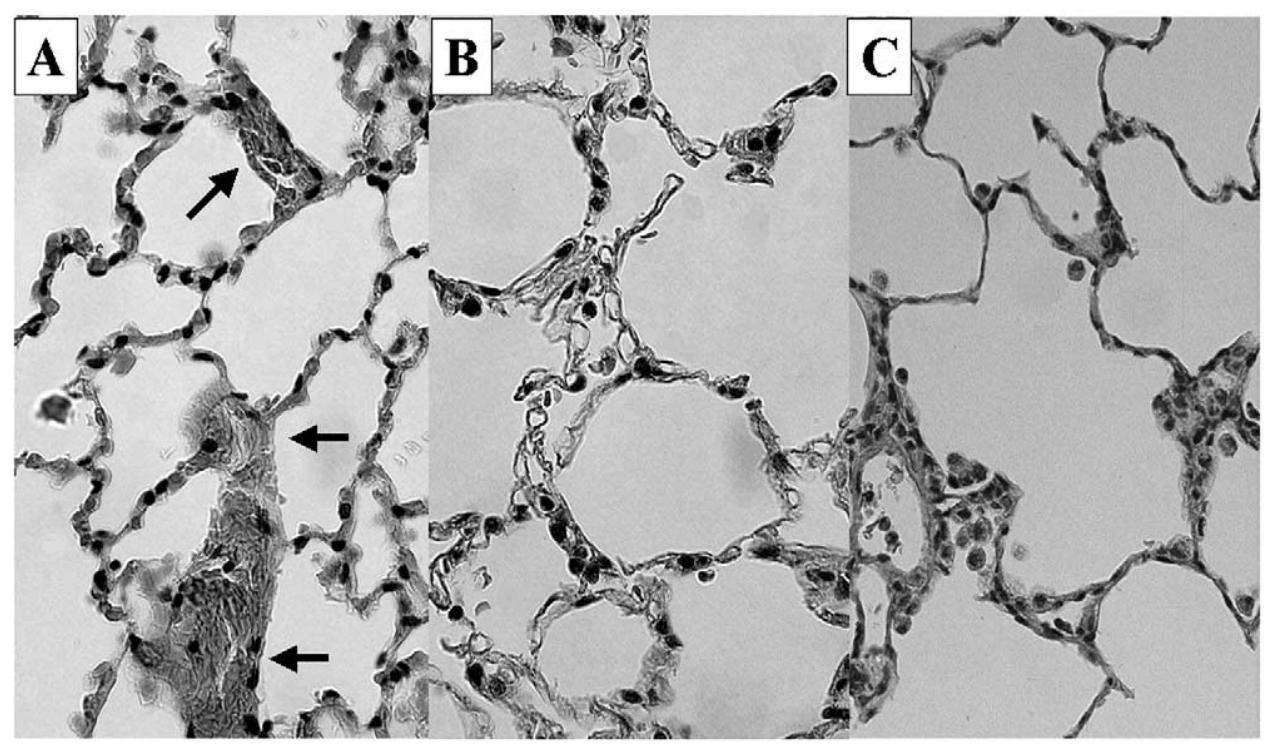

Figure 2. Histologic studies of samples of donor right lung after pulmonary flushing in each group. A, Group 1. B, Group 2. C, Group 3. Many residual blood cells or clots were observed in capillary, as indicated by arrows in group 1. Blood cells or blood clots were less observed in groups 2 and 3.

Because cardiac arrest occurs under very different conditions, two classes of non-heart-beating donors, controlled and uncontrolled, have been distinguished. ${ }^{17}$ Controlled non-heart-beating donors undergo circulatory arrest after planned withdrawal of life support with a retrieval team standing by. Heparin is usually administered before cardiac arrest to prevent microthrombus formation. Successful transplants from controlled non-heart beating donors have been reported for the kidney, ${ }^{18}$ pancreas, ${ }^{19}$ liver, ${ }^{19,20}$ and lung. ${ }^{19}$ However, heparinizing the donor before death for the purpose of organ donation requires consensus on the ethics, because it could hasten death in donors with brain injury. In fact, the practice is strictly restricted in Japan.

The first successful human lung transplantation from an uncontrolled non-heart beating donor was reported by Steen and colleagues ${ }^{1}$ in 2001 , and it is gathering much attention. The donor was a 54-year-old man who had an acute myocardial infarction. After unsuccessful resuscitation, the patient was declared dead. Heparin was given into a central venous catheter 10 minutes after declaration of death, followed by 20 chest compressions. With an intrapleural cooling technique, the right lung was transplanted successfully into a 54-year-old woman with chronic obstructive pulmonary disease.

Postmortem heparinization by closed-chest cardiac massage is potentially problematic because it could cause pulmonary contusion and could deliver microthrombi and toxic cytokines to the lungs from venous blood. We hypothesized that postmortem heparinization by cardiac massage would improve overall lung function by preventing microthrombus

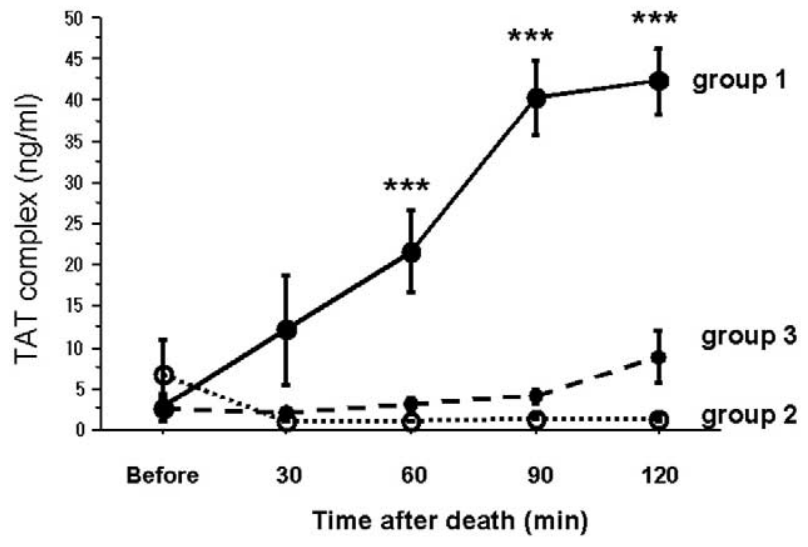

Figure 3. Changes in TAT complex concentration in each group. TAT complex concentration in group 1 significantly increased after death and was significantly higher than in groups 2 and 3 after 60 minutes of warm ischemic time. Concentrations were stable in both groups 2 and 3 after death, and there was no significant difference between these groups. Triple asterisks indicate $P<.001$ versus group 1 .

formation in lung transplantation from non-heart-beating donors.

In this study, heparin was given intravenously $10 \mathrm{~min}$ utes after cardiac arrest in group 3. Equivalent pulmonary functions were obtained in groups 2 (premortem heparinization) and 3 (postmortem heparinization), whereas group 1 (no heparinization) showed worse pulmonary function. It was clearly shown that postmortem heparinization by 
closed-chest cardiac massage improved gas exchange and lowered pulmonary vascular resistance (Table 1). Prevention of microthrombus formation by postmortem heparinization was confirmed macroscopically (Figure 1, $A-C$ ) and microscopically (Figure 2, $A-C$ ). Prolonged ACT in group 3 demonstrated that systemic heparinization could be achieved by closed-chest cardiac massage for 2 minutes. Significant inhibition of the clotting system was also demonstrated by the changes in TAT complex in group 3 (Figure 3).

Postmortem heparinization by closed-chest compression can be achieved easily by anyone, anywhere, without special equipment. It should be also emphasized that no skin incision is required. It therefore can be readily applied to uncontrolled non-heart-beating donors, including those dead on arrival at the hospital. However, it would be essential to administer heparin shortly after cardiac arrest. Further study is needed to determine the optimal time for postmortem heparinization in lung transplantation from non-heartbeating donors.

We acknowledge the expert technical assistance of Tetsuo Kawakami and the statistical advice of Richard B. Schuessler, $\mathrm{PhD}$.

\section{References}

1. Steen S, Sjöberg T, Pierre L, Liao Q, Eriksson L, Algotsson L. Transplantation of lungs from a non-heart-beating donor. Lancet. 2001;357:825-9.

2. Egan TM, Lambert CJ, Reddick R, Ulicny KS, Keagy BA, Wilcox BR. A strategy to increase the donor pool: use of cadaver lungs for transplantation. Ann Thorac Surg. 1991;52:1113-21.

3. Ulicny KS, Egan TM, Lambert CJ, Reddick RL, Wilcox BR. Cadaver lung donors: effect of preharvest ventilation on graft function. Ann Thorac Surg. 1993;55:1185-91.

4. Gu YJ, de Haan J, Brenken UP, de Boer WJ, Prop J, van Oeveren W. Clotting and fibrinolytic disturbance during lung transplantation: effect of low-dose aprotinin. J Thorac Cardiovasc Surg. 1996;112:599-606.

5. Date H, Matsumura A, Manchester JK, Obo H, Lima O, Cooper JM, et al. Evaluation of lung metabolism during successful twenty-fourhour canine lung preservation. J Thorac Cardiovasc Surg. 1993;105: 480-91.
6. Starnes VA, Barr ML, Cohen RG, Hagen JA, Wells WJ, Horn MV, et al. Living-donor lobar lung transplantation experience: intermediate results. J Thorac Cardiovasc Surg. 1996;112:1284-91.

7. Date H, Aoe M, Nagahiro I, Sano Y, Andou A, Matsubara H, et al. Living-donor lobar lung transplantation for various lung diseases. J Thorac Cardiovasc Surg. 2003;126:476-81.

8. Sundaresan S, Semenkovich J, Ochoa L, Richardson G, Trulock EP, Cooper JD. Successful outcome of lung transplantation is not compromised by the use of marginal donor lungs. J Thorac Cardiovasc Surg. 1995; 109:1075-9.

9. Veith FJ, Sinha SB, Graves JS, Boley SJ, Dougherty JC. Ischemic tolerance of the lung. The effect of ventilation and inflation. $J$ Thorac Cardiovasc Surg. 1971;61:804-10.

10. Date H, Matsumura A, Manchester JK, Cooper JM, Lowry OH, Cooper JD. Changes in alveolar oxygen and carbon dioxide concentration and oxygen consumption during lung preservation. The maintenance of aerobic metabolism during lung preservation. $J$ Thorac Cardiovasc Surg. 1993;105:492-501.

11. Roberts CS, Hennington MH, D'Armini AM, Griffith PK, Lemasters JJ, Egan TM. Donor lungs from ventilated cadavers. Impact of a free radical scavenger. J Heart Lung Transplant. 1996;15:275-82.

12. Steen S, Ingemansson R, Budrikis A, Bolys R, Roscher R, Sjöberg T. Successful transplantation of lungs topically cooled in the non-heartbeating donor for 6 hours. Ann Thorac Surg. 1997;63:345-51.

13. Kishima H, Takeda S, Miyoshi S, Matsumura A, Minami M, Utsumi $\mathrm{T}$, et al. Microvascular permeability of the non-heart-beating rabbit lung after warm ischemia and reperfusion: role of neutrophil elastase. Ann Thorac Surg. 1998;65:913-8.

14. Takashima S, Date H, Aoe M, Yamashita M, Andou A, Shimizu N. Short-term inhaled nitric oxide in canine lung transplantation from non-heart-beating donor. Ann Thorac Surg. 2000;70:1679-83.

15. Umemori Y, Date H, Uno K, Aoe M, Ando A, Shimizu N. Improved lung function by urokinase infusion in canine lung transplantation using non-heart-beating donors. Ann Thorac Surg. 1995;47:329-37.

16. Hayama M, Date H, Oto T, Aoe M, Andou A, Shimizu N. Improved lung function by means of retrograde flush in canine lung transplantation with non-heart-beating donors. J Thorac Cardiovasc Surg. 2003;125:901-6.

17. Kootstra G, Daemen JH, Oomen AP. Categories of non-heart beating donors. Transplant Proc. 1995;27:2893-4.

18. Koffman G, Gambaro G. Renal transplantation from non-heart-beating donors: a review of the European experience. J Nephrol. 2003;16:33441.

19. D'Alessandro AM, Hoffmann RM, Knechtle SJ, Eckhoff DE, Love RB, Kalayoglu M, et al. Successful extrarenal transplantation from non-heart-beating donors. Transplantation. 1995;59:977-82.

20. Reich DJ, Munoz SJ, Rothstein KD, Nathan HM, Edwards JM, Hasz $\mathrm{RD}$, et al. Controlled non-heart-beating donor liver transplantation. Transplantation. 2000;70:1159-66. 